\title{
THE CONCENTRATION AND BINDING OF THYROXINE AND TRIIODOTHYRONINE BY RAT DIAPHRAGM ${ }^{1}$
}

\author{
By JOHN R. HOGNESS, NORMAN D. LEE, MARGARET K. BERG, AND \\ ROBERT H. WILLIAMS \\ (From the Department of Medicine, University of Washington School of Medicine, Seattle, \\ Wash., and the Radioisotope Service, Veterans Administration Teaching Group \\ Hospital, Memphis, Tenn.)
}

(Submitted for publication December 21, 1956; accepted February 14, 1957)

Thyroid hormone has long been thought to exert its primary effect in the peripheral tissues. Recent studies have indicated, however, that thyroxine may be converted to other products in these tissues before becoming metabolically active (1-4). Whether or not a subsequent alteration is necessary, it seems probable that the thyroxine must first be fixed in some form of physicochemical union, either on the surface of, or inside the cell, before it can exert its characteristic effect on the metabolism of the tissue.

Probably the most complete study of this sort has been carried out by Stadie on the binding in vitro of insulin to various rat tissues, particularly diaphragm $(5,6)$. With respect to thyroxine and triiodothyronine, Hamolsky and Crispell and coworkers have studied the effect of plasma on the binding of these hormones to red blood cells in vitro (7-9) and Gross has reported similar studies relative to liver slices (10).

Since one significant site of thyroid hormone localization seems to be the muscle mass of the body (11), it should be of interest to study the binding in vitro of thyroxine to a specific tissue such as rat diaphragm. In fact, one such study has been reported by Hamolsky and Freedberg (12) who investigated differences in the rate of uptake by rat diaphragm of thyroid hormone from the plasma of normals and thyrotoxic patients. The purpose of this report is to present information on the nature of the binding phenomenon exhibited by rat diaphrgam in vitro, relative to thyroxine and triiodothyronine labeled with $\mathrm{I}^{\mathbf{1 3 1}}$.

\section{MATERIALS AND METHODS}

Hemidiaphragms from 200-Gm. male Sprague-Dawley rats were used throughout the experiment. All rats were

\footnotetext{
1 Supported in part by grants from the U. S. Atomic Energy Commission and the U. S. Public Health Service.
}

bred in our labortory and maintained at a constant room temperature on Purina laboratory chow.

Diaphragms were removed from the rats after ether anesthesia, bisected, weighed and immediately immersed in $5 \mathrm{ml}$. of phosphate buffer (5) containing varying amounts of $\mathrm{I}^{181}$-labeled 1-thyroxine or 1-triiodothyronine ${ }^{2}$ and incubated at $37^{\circ} \mathrm{C}$. in a Dubnoff shaker for varying periods of time according to the conditions of the experiments. After removal from the incubating beakers the hemidiaphragms were rinsed three times in $25 \mathrm{ml}$. of ice cold phosphate buffer. The first two rinses were always of 30 seconds' duration and the time of the third rinse varied as indicated in each experiment. After the third rinse, the tissue was dissolved in a constant volume of 30 per cent $\mathrm{KOH}$ and the radioactivity in the solution determined with a well-type gamma counter. Results are expressed in terms of micromoles bound per $100 \mathrm{mg}$. of diaphragm as determined by calculation from the specific activity of the labeled compounds used. Comparison studies, using $\mathrm{NaI}^{121}$, were carried out under similar conditions.

All points in all experiments reported represent the average values for 12 hemidiaphragms. The range of values was wide in some instances (see Figure 1) and it was found necessary to use this number of hemidiaphragms to obtain statistically significant results. Both hemidiaphragms from the same animal were never used in the determination of a single point.

\section{EXPERIMENTAL CONDITIONS AND RESULTS}

\section{Incubation time}

In order to determine the effect of increasing time of incubation on the binding of thyroxine by rat muscle, hemidiaphragms were incubated with concentrations of $\mathrm{I}^{131}$-labeled thyroxine ranging from $1.3 \times 10^{-4}$ through $26.0 \times 10^{-4} \mu \mathrm{M}$ per $\mathrm{ml}$. for intervals of $1,5,15,30,60,120$, or $240 \mathrm{~min}$ utes. The third rinse was of 30 minutes' duration in all cases.

Figure 1 shows the results of this study when

2 Obtained from Abbott Laboratories, Oak Ridge, Tennessee. Both hormones were labeled in the position ortho to the hydroxyl group. 


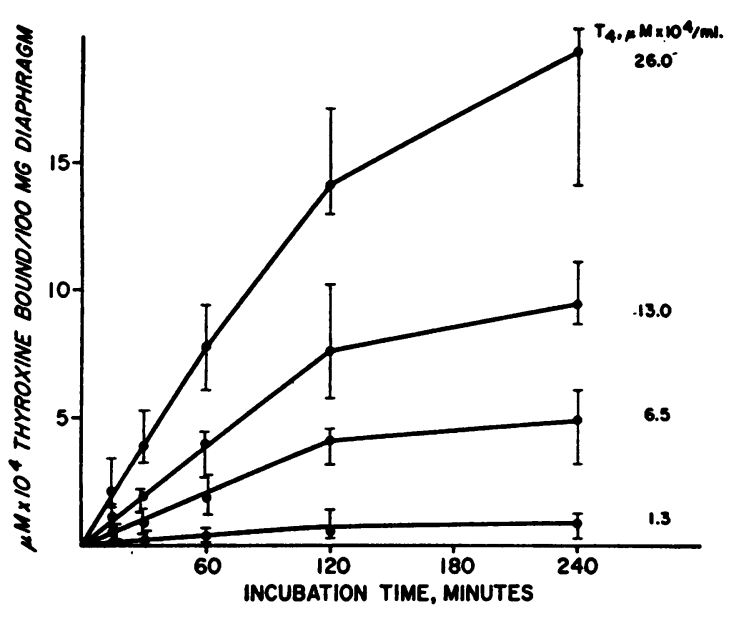

Fig. 1. Binding of Thyroxine-I ${ }^{121}$ to Rat Diaphragm WITH INCREASING INCUbation Time

Concentration of thyroxine (T4) in incubation medium is shown at the right. In this and all subsequent figures, concentrations along ordinates or when listed in a column are multiplied by $10^{4}$ to give unit values, i.e., $26 \times 10^{-4} \times$ $10^{4}=26$. Hence ordinates are labeled $\mu \mathrm{M} \times 10^{4}$ indicating multiplication by this factor. Ranges of values are indicated by the thin vertical line at each point and are presented as an illustrative example in Figure 1 only.

the amount of thyroxine- $\mathrm{I}^{131}$ fixed to tissue is plotted against time. The figures at the end of each curve indicate the hormone concentration in the incubation medium. It can be seen that at each concentration the amount of thyroxine bound was linearly related to time for approximately 120 minutes: there appeared to be some decrease in

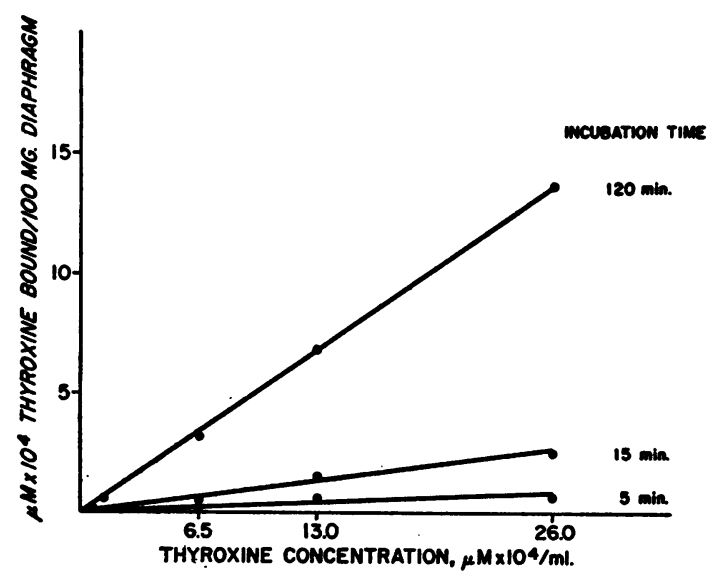

Fig. 2. Binding of Thyroxine- ${ }^{131}$ to Rat Diaphragm as a Function of Thyroxine Concentration in Incubating Medium

Incubation time is shown at right. the rate of uptake by 240 minutes. Recalculation of these figures in relative terms (Table I) shows that the per cent of available thyroxine- ${ }^{131}$ bound at any given time was independent of its concentration in the medium over the 240-minute period studied.

It is of some significance to point out that, regardless of the initial concentration of the hormone and despite rinsing for over 30 minutes, the concentration of thyroxine bound to diaphragm very closely approximated that in the medium within 15 minutes and clearly exceeded this amount by 30 minutes.

\section{The role of thyroxine concentration}

The above experiments were repeated and the results are presented in Figure 2, wherein the con-

\section{TABLE I}

Per cent of available thyroxine bound to rat diaphragm with increasing incubation time*

\begin{tabular}{cc}
\hline $\begin{array}{c}\text { Incubation } \\
\text { time } \\
\text { Minules }\end{array}$ & $\begin{array}{c}\text { Per cent available } \\
\text { thyroxine bound per } \\
\text { 100 mg. diaphragm }\end{array}$ \\
\hline 15 & $0.7(0.6-0.8)$ \\
30 & $2.7(2.2-3.5)$ \\
60 & $6.0(5.7-6.3)$ \\
120 & $10.5(8.0-12.9)$ \\
240 & $14.6(13.5-15.4)$
\end{tabular}

* Thyroxine concentration ranged from $1.3 \times 10^{-4} \mu \mathrm{M}$ per ml. through $26.0 \times 10^{-4} \mu \mathrm{M}$ per ml.

centration of thyroxine- $\mathrm{I}^{131}$ initially present in the incubation medium is plotted against the amount of hormone bound per $100 \mathrm{mg}$. of rat hemidiaphragm after incubation for 5, 15 and 120 minutes. It should be noted that these intervals represent times prior to, and subsequent to, the achievement of tissue concentrations of the hormone greater than those initially present in the medium (Figure 1). It may be seen that, regardless of these intervals, there was a direct linear relationship between the amount of thyroxine available for binding and amount that was bound by the hemidiaphragms. Consequently, these experiments show that for concentrations up to $26 \times 10^{-4} \mu \mathrm{M}$ per $\mathrm{ml}$. and for incubation periods up to 120 minutes, no limit of the concentrating and binding ability of the tissue had been reached. 
The relationship between rinsing time and thyroxine-I ${ }^{181}$ binding

To determine the rate at which radioactivity can be removed from diaphragm after incubation with thyroxine- ${ }^{131}$, and hence to determine the degree of binding to the tissue, the following experiment was designed. Hemidiaphragms were incubated in buffer containing $1.3 \times 10^{-4}, 6.5 \times 10^{-4}$ or $13.0 \times 40^{-4} \mu \mathrm{M}$ of thyroxine-I ${ }^{181}$ per $\mathrm{ml}$. for 1 , 15 or 120 minutes. They were then rinsed as described previously except the third rinse lasted 1 , $5,15,30$ or 45 minutes. Results of studies, where incubation was carried out for 1 minute and 120 minutes are shown in Figures 3 and 4. These curves are strikingly similar to those obtained by Stadie, Haugaard, and Vaughen (6) for insulin$\mathrm{I}^{181}$ under similar conditions and indicate that little thyroxine- $\mathrm{I}^{131}$ is removed from muscle after rinsing for approximately 15 minutes. Furthermore, these results support the view that, of the total thyroxine associated with the tissue, the amount firmly bound is proportional to the concentration in the medium.

\section{Equilibrium studies}

In a further attempt to elucidate the nature of the binding of thyroxine to muscle tissue, equilibrium studies were carried out using non-labeled thyroxine. Hemidiaphragms were incubated in buffer containing $1.3 \times 10^{-4}, 6.5 \times 10^{-4}$ or $13.0 \times$ $10^{-4} \mu \mathrm{M}$ of thyroxine- $\mathrm{I}^{181}$ per $\mathrm{ml}$. for up to 120 minutes. The length of the third rinse was 30 minutes in all instances.

For each concentration, 12 hemidiaphragms were removed at the 15-minute point and assayed for radioactivity. At 60 minutes a second set of 12 hemidiaphragms was removed and assayed while a third set was rinsed twice for 30 seconds and transferred to an identical solution containing non-radioactive thyroxine. After an additional 60 minutes' incubation in this solution, the hemidiaphragms were rinsed for 30 minutes in buffer and the radioactivity determined as before. A fourth set was incubated in the radioactive thyroxine solution for the full 120 minutes. The results are presented in Figure 5.

The results of this equilibrium study show that little or none of the thyroxine- ${ }^{131}$ bound to muscle during the first 60 minutes of incubation was lost

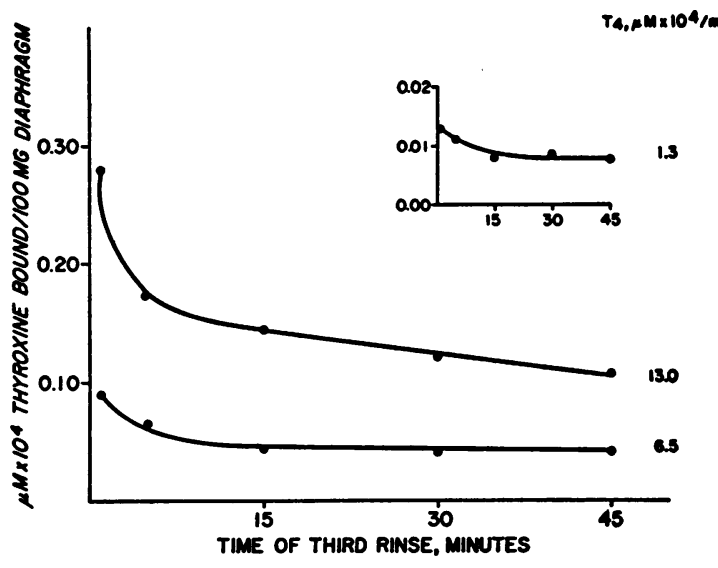

Fig. 3. Amount of Thyroxine-I ${ }^{\text {in }}$ Bound to Rat Diaphragm after Incubation for ONe Minute and Rinsing for Increasing Periods of Time

Concentration of thyroxine (T4) in incubating medium is shown at right.

by incubation with unlabeled thyroxine for another equal period of time at any of the concentrations used. This study confirms the view that the concentration of thyroxine by muscle involves a firm binding rather than the gradual approximation of an equilibrium state. It would appear probable that once a molecule of thyroxine is fixed to tissue it is not released as such but rather as some conversion product.

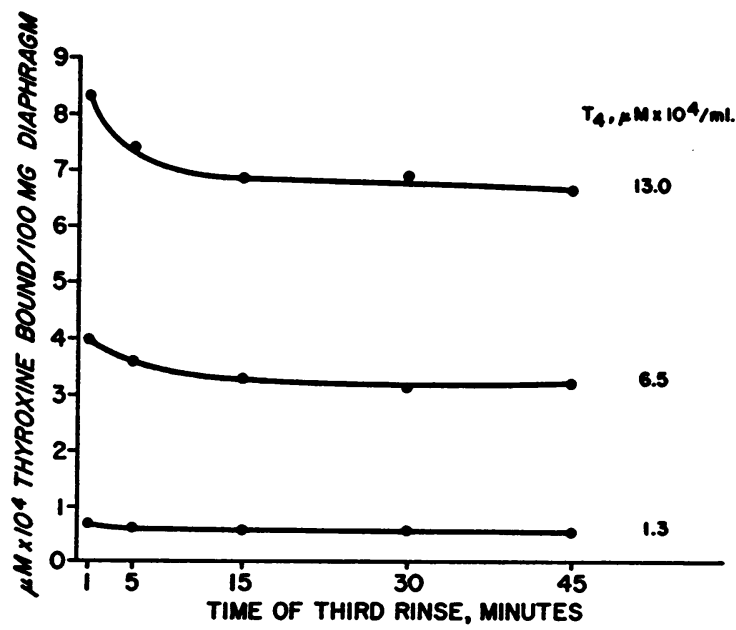

Fig. 4. Amount of Thyroxine-Im Bound to Rat DIAPHRAgm AFter InCUBation fOR 120 Minutes AND Rinsing for Increasing Periods of Time

Concentration of thyroxine (T4) in incubating medium is shown at right. 


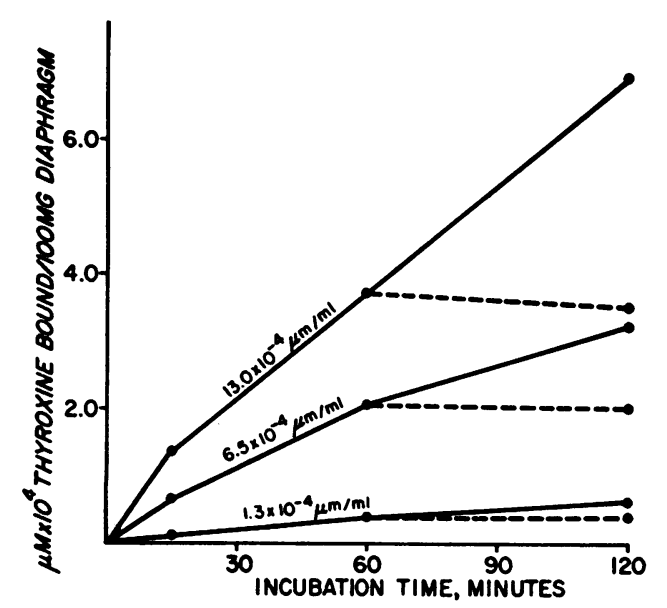

Fig. 5. EQUilibrium StUdY-Thyroxine-I ${ }^{19}$ Bound to Rat Diaphragm with Increasing Incubation TIME

At the 60-minute point diaphragms were removed and incubated in non-labeled thyroxine for an additional 60 minutes. Solid line indicates thyroxine- $\mathrm{I}^{181}$ in incubation medium; broken line indicates transfer to unlabeled thyroxine.

\section{Binding and washout of triiodothyronine}

Since triiodothyronine has been shown to act much more rapidly than thyroxine in raising the oxygen consumption of both animals and man (13-16) it seemed of interest to determine whether the binding of this compound by rat muscle differed from that of thyroxine.

Hemidiaphragms were incubated as described previously in buffer containing $1.3 \times 10^{-4} \mu \mathrm{M}$ of

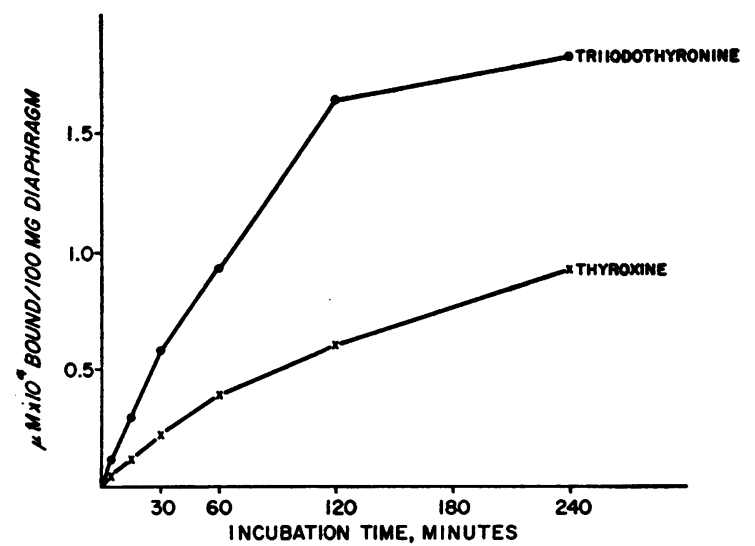

Fig. 6. Comparison of Rate of Binding of ThyROXINE-I ${ }^{181}$ AND TRIIODOTH YRONINE-I ${ }^{131}$ to RAT DIAPHRAGM

Hormone concentration in the incubation medium was $1.3 \times 10^{-4} \mu \mathrm{M}$ per $\mathrm{ml}$. triiodothyronine- $\mathrm{I}^{131}$ per $\mathrm{ml}$. for periods of 1,5 , $15,30,60,120$ or 240 minutes and were rinsed 3 times, the third rinse lasting 30 minutes. The values obtained are presented in Figure 6 along with those from an identical experiment using thyroxine-I ${ }^{131}$.

It is evident that triiodothyronine- $\mathrm{I}^{131}$ is much more rapidly bound to rat diaphragm than is thyroxine- $\mathrm{I}^{131}$. Furthermore, with one exception and regardless of the incubation interval, the ratio (triiodothyronine bound/ thyroxine bound) is quite constant, varying from 2.4 to 2.7 ; the exception occurs at 240 minutes, the ratio dropping to slightly less than 2. Various explanations for this drop may be offered; it is significant, however, that by 240 minutes almost 30 per cent of the available hormone had been firmly bound and, reasoning from the data in Figure 3, probably another 30 per cent was loosely entrapped in the tissue.

Washout studies similar to those carried out with thyroxine- $\mathrm{I}^{131}$ were performed with triiodothyronine- $\mathrm{I}^{131}$. Hemidiaphragms were incubated for 1,5 and 15 minutes in buffer containing $1.3 \times$ $10^{-4} \mu \mathrm{M}$ per ml. of triiodothyronine- $\mathrm{I}^{131}$. The third rinse was carried out for 15, 30 and $45 \mathrm{~min}$ -

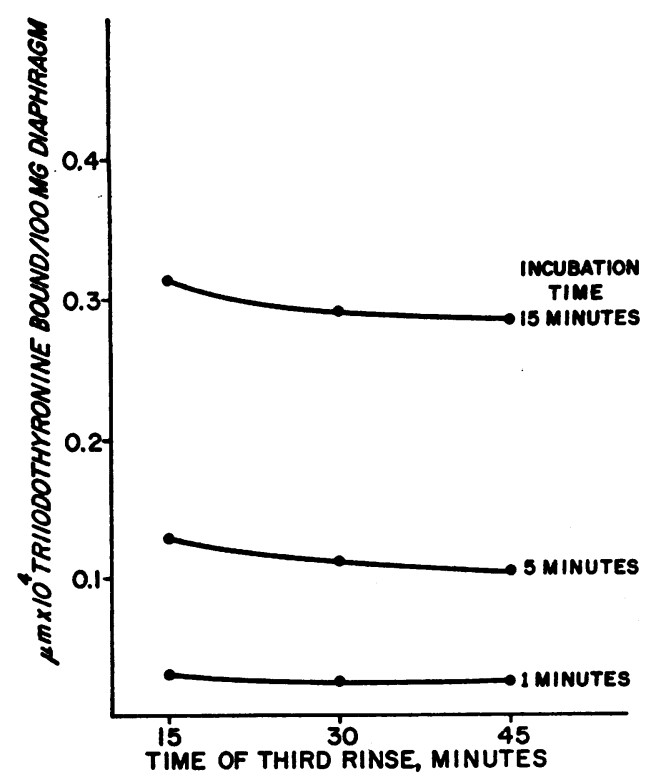

Fig. 7. Amount of Triodothyronine Bound to Rat DiAPHRAGM AFTER INCUBATION FOR 1, 5 AND 15 MINUTES and Rinsing for Increasing Periods of Time

Concentration of triiodothyronine was $1.3 \times 10^{-4} \mu \mathrm{M}$ per $\mathrm{ml}$. 
utes. The results are presented in Figure 7. Comparison with Figures 3 and 4 shows the washout curves for triiodothyronine- $\mathrm{I}^{131}$ to be almost exactly parallel to those for thyroxine- $I^{131}$. The concentration of triiodothyronine- $\mathrm{I}^{\mathbf{1 3 1}}$ in the tissue was consistently higher than that shown in the thyroxine- $\mathrm{I}^{131}$ concentration studies.

\section{NaI $I^{131}$ studies}

It is important to establish, in relative terms, to what extent iodide- $\mathrm{I}^{131}$ ion might influence the results presented in previous sections. Consequently, a study was conducted in which hemidiaphragms were incubated for various periods of time up to 240 minutes in buffer containing $6.5 \times$ $10^{-4} \mu \mathrm{M}$ per ml. of sodium iodide- ${ }^{181}$. The third rinse was for 30 minutes. Figure 8 presents the results for this experiment; the curve for a similar experiment involving an equimolar concentration of thyroxine- $\mathrm{I}^{131}$ is presented for comparison. The amount of $\mathrm{NaI}^{131}$ bound to muscle was clearly different from the amount of thyroxine- $\mathrm{I}^{131}$ bound and was, in quantitative terms, insignificant.

Washout studies similar to the experiment represented by Figures 3 and 4 produced the results shown in Figure 9. In the instance shown, the diaphragms were incubated for 120 minutes in medium containing $6.5 \times 10^{-4} \mu \mathrm{M} \mathrm{NaI}{ }^{131}$ per ml. and the third wash was of 15,30 and 45 minutes' duration. This study indicated a rapid and con-

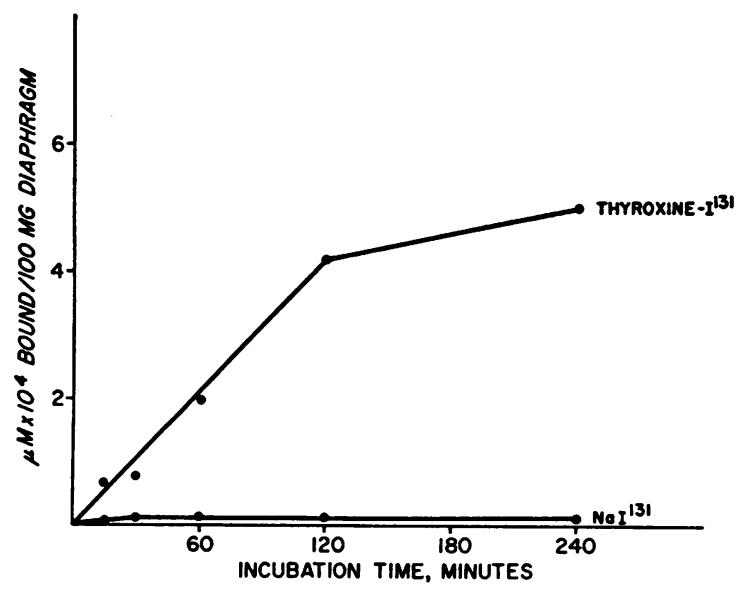

Fig. 8. Comparison of Rate and Amount of Binding of Thyroxine-I ${ }^{181}$ and NaI ${ }^{181}$ to Rat Diaphragm

Concentration of both compounds was $1.3 \times 10^{-4} \mu \mathrm{M}$ per $\mathrm{ml}$.

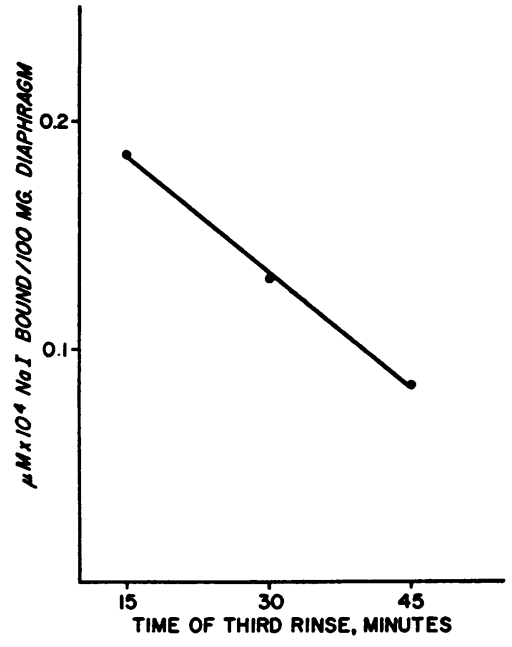

Fig. 9. Amount of NaI ${ }^{13}$ Remaining in Rat DiaPhragm with Rinsing For Increasing Periods of TIME

Diaphragms were first incubated for 120 minutes in medium containing $6.5 \times 10^{-4} \mu \mathrm{M} \mathrm{NaI}{ }^{18 s}$ per ml.

tinued loss of $\mathrm{NaI}^{131}$ from tissue as the rinsing period was prolonged; furthermore, the slope of this curve differed from those for thyroxine- $\mathrm{I}^{131}$ and triiodothyronine- $\mathrm{I}^{131}$.

\section{DISCUSSION}

As pointed out by Stadie it would seem reasonable that the Michaelis-Menten concept of enzymesubstrate interaction must also hold for enzymehormone relationship within tissues. In other words "the hormone must approach within molecular distance of the enzyme, otherwise it would be difficult to conceive how the hormone could affect enzymatic action" (17). Thyroxine (and triiodothyronine) must, therefore, first be bound in some fashion to, or within, the cell. The studies reported in this paper indicate that in the case of muscle, in vitro, binding does indeed occur. The observations presented here could not be explained on the basis of passive diffusion alone for the following reasons: 1 ) In the incubation time studies, it can be noted that the concentration of thyroxine$\mathrm{I}^{131}$ in the diaphragm exceeded that of the incubating medium after an incubation period of about 15 to 20 minutes. Since no corrections for tissue water are taken into account here, the true concentrations in the tissue must have been even higher. 2) The washout studies showed that, 
although the initial loss of activity from the tissues was high, the curves level off after about $15 \mathrm{~min}$ utes of washing, indicating fixation of the remaining thyroxine- $\mathrm{I}^{\mathbf{1 3 1}}$ to the tissue. 3) Perhaps the most convincing evidence for true chemical binding is the equilibrium studies. It was demonstrated that little or no thyroxine-I ${ }^{131}$ was removed from the diaphragm by continued incubation in solutions containing equal concentrations of nonradioactive thyroxine. 4) The studies with triiodothyronine- $\mathrm{I}^{131}$ and the marked difference between the uptake of this substance and thyroxine- $\mathrm{I}^{131}$ by rat diaphragm indicate again that a specific binding occurred and that this was different in degree depending, perhaps, upon the physiological activity of the compound studied. Certainly, if only passive diffusion into the tissue was involved, one might expect little difference between these chemically similar compounds. The uptake and washout studies with $\mathrm{NaI}^{131}$, where binding by the tissue was far different in degree from that observed with thyroid hormone, lend further support to the concept of specific binding of thyroxine and triiodothyronine.

It is of some interest to note that binding of these hormones to tissue is probably not the sole mechanism for their removal from the incubation medium. The two preliminary rinses for $30 \mathrm{sec}$ onds each removed the major portion of the labeled hormone that was held in the surface film of fluid on the diaphragm, yet it took more than 15 minutes to remove what appeared to be unbound thyroxine (Figures 3 and 4 ) from the tissue. In view of the fact that the initial values in these figures were also proportional to both the incubation time and concentration of hormone in the medium, it seems only reasonable to suggest that both thyroxine and triiodothyronine were actively transported from the medium into the cell where binding to cellular loci took place resulting in the firm fixation reported in these experiments. The remaining unbound hormone within the cell was available for diffusion back into the medium. Compartmentalization of this type within the cell has previously been reported in rat liver (18).

The observation that triiodothyronine is much more rapidly bound to muscle tissue than is thyroxine corresponds well with observations in man that this substance acts four to five times as rap- idly as thyroxine in raising the oxygen consumption of intact animals. After 120 minutes, for example, almost three times as much triiodothyronine- $\mathrm{I}^{131}$ was incorporated as was thyroxine- $\mathrm{I}^{131}$. However, since both substances are bound to the tissue this experiment neither supports nor contradicts the hypothesis that thyroxine must be converted to triiodothyronine before becoming physiologically active.

Finally, it would seem that since thyroxine and triiodothyronine are specifically bound to rat diaphragm, this observation may offer a convenient means of studying the effects of varying in vivo and in vitro conditions on the peripheral action of these compounds. Furthermore, the rate of active transport and binding of these hormones may be a factor of paramount significance in understanding the mechanism of their action. In this regard, it has been observed that an increased rate of peripheral degradation of thyroxine- $\mathrm{I}^{131}$ was coincident with increased thyroidal activity in clinically euthyroid relatives of patients with Graves' disease (19). The role of active transport and binding of thyroid hormone may well be one of the regulatory factors in maintaining the euthyroid state.

\section{SUMMARY}

Studies of the uptake of $I^{131}$-labeled thyroxine by rat diaphragm as a function of incubation time, hormone concentration in the medium and duration of rinsing, as well as equilibrium studies, are presented. When rat diaphragm was incubated in medium containing varying concentrations of thyroxine for increasing periods of time, the amount of the hormone bound was shown to be linearly related to the time of incubation at all concentrations. Similarly, a direct linear relationship between the amount of thyroxine available and the amount bound to tissue was demonstrated. Washout studies showed that, with prolonged rinsing, little thyroxine was removed from rat muscle after the first 15 minutes of rinsing. Equilibrium studies, wherein hemidiaphragms were incubated first with labeled thyroxine and then transferred to solutions containing unlabeled material, showed no significant loss of initial radioactivity during incubation with the non-radioactive thyroxine. All of these observations indicate that thyroxine is indeed specifically bound to rat muscle tissue in 
concentrations far exceeding those in the incubating medium.

Similar incubation and washout studies were carried out with triiodothyronine. These studies showed not only that triiodothyronine was also specifically bound to rat muscle tissue but that this binding took place much more rapidly than in the case of thyroxine. When the hormone concentration was $1.3 \times 10^{-4} \mu \mathrm{M}$ per ml. triiodothyronine$\mathrm{I}^{131}$ was bound to rat diaphragm 2.5 times as rapidly as was thyroxine- $\mathrm{I}^{181}$. This finding is in accord with previous observations regarding the relative rates of action of these two compounds in vivo.

Comparison studies carried out with $\mathrm{NaI}^{131}$ showed that, in equimolar concentrations, relatively insignificant amounts of this compound were taken up by rat diaphragm and that which was absorbed was readily removed by washing.

These investigations are discussed in relation to the mechanism of action of thyroxine and triiodothyronine.

\section{REFERENCES}

1. Gross, J., and Pitt-Rivers, R., Physiological activity of $3: 5: 3^{\prime}$-L-triiodothyronine. Lancet, 1952, 1, 593.

2. Albright, E. C., Larson, F. C., and Tust, R. H., In vitro conversion of thyroxin to triiodothyronine by kidney slices. Proc. Soc. Exper. Biol. \& Med., 1954, 86, 137.

3. Maclagan, N. F., and Sprott, W. E., The in-vitro deiodination of thyroxine and triiodothyronine. Lancet, 1954, 2, 368.

4. Hogness, J. R., Berg, M., VanArsdel, P. P., Jr., and Williams, R. H., Tissue conversion of thyroxine to triiodothyronine. Proc. Soc. Exper. Biol. \& Med., 1955, 90, 93.

5. Stadie, W. C., Haugaard, N., Marsh, J. B., and Hills, A. G., The chemical combination of insulin with muscle (diaphragm) of normal rat. Am. J. M. Sc., 1949, 218, 265.

6. Stadie, W. C., Haugaard, N., and Vaughan, M., Studies of insulin binding with isotopically labeled insulin. J. Biol. Chem., 1952, 199, 729.
7. Hamolsky, M. W., The plasma protein-thyroid hormone complex in thyrotoxicosis vs. euthyroidism in man. J. Clin. Invest., 1955, 34, 914.

8. Crispell, K. R., Kahana, S., and Hyer, H., The effect of plasma on the in vitro uptake or binding by human red cells of radioactive I-131 labeled L-thyroxine and L-triiodothyronine. J. Clin. Invest., 1956, 35, 121.

9. Crispell, K. R., and Coleman, J., A study of the relative binding capacity of plasma proteins, intact human red cells, and human red cell stroma for radioactive I-131 labeled L-thyroxine. J. Clin. Invest., 1956, 35, 475.

10. Gross, J., and Pitt-Rivers, R., Triiodothyronine in relation to thyroid physiology. Rec. Prog. Hormone Research, 1954, 10, 109.

11. VanArsdel, P. P., Jr., Hogness, J. R., Williams, R. H., and Elgee, N., Comparative distribution and fate of $\mathrm{I}^{121}$-labeled thyroxine and triiodothyronine. Endocrinology, 1954, 55, 332.

12. Hamolsky, M. W., and Freedberg, A. S., The circulating thyroid hormone-plasma protein complex in euthyroid and hyperthyroid subjects. Differences in rate of disappearance in dogs and "uptake" by rat diaphragm. Tr. Am. A. Study Goiter, 1954, 269.

13. Tomich, E. B., and Woollett, E. A., The biological activity of triiodothyronine. Lancet, 1953, 1, 726.

14. Maclagan, N. F., Sprott, W. E., and Wilkinson, J. H., Effect of $3: 5: 3^{\prime}$-L-triiodothyronine and certain anti-thyroxine substances on the oxygen consumption of mice. Lancet, 1952, 2, 915.

15. Heming, A. E., and Holtkamp, D. E., Comparative effects of thyroxine and triiodothyronine on oxygen consumption of rats. Federation Proc., 1953, $12,330$.

16. Gross, J., Pitt-Rivers, R., and Trotter, W. R., Effect of $3: 5: 3^{\prime}$-L-triiodothyronine in myxoedema. Lancet, 1952, 1, 1044.

17. Stadie, W. C., Current views on the mechanisms of insulin action. Am. J. Med., 1955, 19, 257.

18. Lee, N. D., and Williams, R. H., The intracellular localization of labeled thyroxine and labeled insulin in mammalian liver. Endocrinology, 1954, 54, 5.

19. Ingbar, S. H., Freinkel, N., Dowling, J. T., and Kumagai, L. F., Abnormalities of iodine metabolism in euthyroid relatives of patients with Graves' disease. J. Clin. Invest., 1956, 35, 714. 